\title{
ANALYSIS OF THE EFFECT OF RAIN FREQUENCY ON PERMEABILITY AND PONDONG TIME ON TYPE SOIL COMMON SOIL (Laboratory Testing Study With Rainfall Simulator)
}

\author{
Abdul Rakhim Nanda ${ }^{(1}$ Eki Sandi $^{2)}$ dan Sulvahenra ${ }^{3)}$ \\ ${ }^{1)}$ Universitas Muhammadiyah Makassar, Indonesia \\ Email : rahim_nanda@yahoo.co.id \\ 2) Universitas Muhammadiyah Makassar, Indonesia \\ Email : ekisandi28@gmail.com \\ 3) Universitas Muhammadiyah MakassarMakassar, Indonesia \\ Email : Sulvahenra29@gmail.com
}

\begin{abstract}
Abstrak
Tujuan Penelitian untuk mengetahui pengaruh frekuensi hujan terhadap permeabilitas dan waktu penggenangan dengan frekuensi ulangan hujan yang intensitasnya sama dan intensitas bervariasi pada jenis tanah common soil. Metode Penelitian ini merupakan jenis penelitian eksperimental labolatorium, dengan menggunakan alat rainfall simulator. Tanah yang digunakan dalam penelitian ini adalah jenis tanah common soil. Selanjutnya diberikan hujan buatan dengan intensitas $I_{5}, I_{15}$, dan $I_{25}$, setiap intensitas digunakan frekuensi lima kali hujan dan dilakukan pembacaan waktu final penggenagan dan tinggi genangan pada bak percobaan Rainfall Simulator dan untuk pengujian permeabilitas dilakukan pengamatan dengan uji constand head. Hasil penelitian menunjukkan nilai koefisien permeabilitas berbanding terbalik dengan meningkatnya intensitas curah hujan dan frekuensi hujan.. Tinggi genangan dan Waktu final genangan berbanding lurus dengan meningkatnya intensitas curah hujan dan variasi frekuensi hujan.
\end{abstract}

Kata kunci : permeabilitas, tinggi genangan, waktu final genangan.

\begin{abstract}
The purpose of the study was to determine the effect of rain frequency on permeability and flooding time with rainfall frequencies with the same intensity and intensity varying on common soil soil type. Methods This research is a type of experimental labolatorium research, using rainfall simulator tool. The soil used in this research is common soil soil type. Furthermore, artificial rain with intensity of $I_{5}, I_{15}$, and $I_{25}$ is applied, each intensity is used at five times of rain frequency and the final time of the bursting and puddle in Rainfall Simulator test tube and for permeability testing is done by observation with constand head test. The results showed that the value of permeability coefficient is inversely related to the increase of rainfall intensity and rain frequency. The inundation height and the final time of the puddle are directly proportional to the increased rainfall intensity and rain frequency variation.
\end{abstract}

Keywords: permeability, high inundation, final puddle time. 


\section{PENDAHULUAN}

Hujan merupakan salah satu bentuk presipitasi uap air yang berasal dari alam yang terdapat di atmosfer. Pukulan butir-butir hujan pada permukaan tanah yang terbuka menghancurkan dan mendispersikan aggregat tanah yang mengakibatkan penyumbatan pori tanah di Permukaan.

Permeabilitas tanah sangat penting untuk kemajuan dalam studi ke tersediaan air dan efisiensi aplikasi air, dan dalam desain sistem drainase untuk reklamasi. Koefisien permeabilitas terutama tergantung pada ukuran rata-rata pori yang dipengaruhi oleh distribusi ukuran partikel, bentuk partikel dan struktur tanah. Secara garis besar, makin kecil ukuran partikel, makin kecil pula ukuran pori dan makin rendah koefisien permeabilitasnya.

\section{Intensitas Curah Hujan}

Dalam penelitian ini digunakan rumus Mononobe untuk menghitung intensitas curah hujan.

$$
I=\frac{R_{24}}{24}\left(\frac{24}{t}\right)^{m}
$$

$I=$ intensitas curah hujan (mm/jam)

$$
t=\text { lamanya curah hujan (menit), }
$$
atau untuk 4 dalam (jam) a,b,n,m: tetapan

$R_{24}=$ curah hujan maksimum dalam 24 jam (mm).

\section{Permeabilitas}

Permeabilitas tanah adalah ke mampuan tanah untuk meneruskan air atau udara. Permeabilitas tanah biasanya diukur dengan istilah kecepatan air yang mengalir dalam waktu tertentu yang ditetapkan dalam satuan cm/jam (Hakim, dkk, 1986).

Permeabilitas dapat mempengaruhi kesuburan tanah. Permeabilitas berbeda dengan drainase yang lebih mengacu pada proses pengaliran air saja, permeabilitas dapat mencakup bagaimana air, bahan organik, bahan mineral, udara dan partikel - partikel lainnya yang terbawa bersama air yang akan diserap masuk kedalam tanah (Rohmat, 2009).

\section{Waktu penggenangan}

Waktu penggenangan (ponding time) t_p merupakan selisih waktu antara saat hujan turun dan waktu dimana air

Dimana : 
mulai menggenang diatas permukaan tanah.

\section{Pengukuran permeabilitas dan waktu penggenangan}

Hukum Darcy menjelaskan tentang kemampuan air mengalir pada ronggarongga (pori) dalam tanah dan sifatsifat yang mempengaruhi-nya. Dalam penelitian ini untuk pengukuran nilai permeabilitas tanah menggunakan alat constand head dan untuk pengamatan waktu final penggenangan dan waktu genangan menggunakan alat simulasi hujan (rainfall simulator).

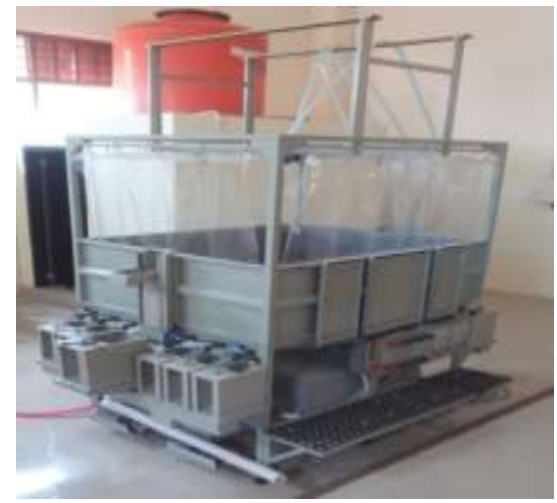

Gambar 1. Alat Simulasi hujan (Rainfall Simultor)

Berdasarkan Standart untuk intensitas curah hujan pada alat rainfall simulator hujan buatan yang ditentukan oleh Departemen Pertahanan Amerika Serikat (United States Department of Difense (DOD) MIL-STD-810F. Method 506.4 standard), maka telah ditentukan standart intensitas curah hujan untuk rainfall simulator pada beberapa kondisi hujan.

Dalam penelitian ini menggunakan standart tersebut, berikut ditampilkan standart intensitas curah hujan pada alat Rainfall Simulator yang digunakan dalam penelitian ini.

Tabel 1. Standar Intensitas Curah hujan pada Rainfall Simulator

\begin{tabular}{|c|c|c|}
\hline Rain Condidtion & Rain Fall Rate & Flow Rates \\
\hline \multirow{3}{*}{ Extreme } & More than : $14 \mathrm{~mm} / \mathrm{min}$ & \multirow{3}{*}{ More than : $16,8 \mathrm{~L} / \mathrm{min}$} \\
\hline & $840 \mathrm{~mm} / \mathrm{hour}$ & \\
\hline & $33.1 \mathrm{inchi} /$ hour & \\
\hline \multirow{3}{*}{ High } & $8 \mathrm{~mm} / \mathrm{min}-14 \mathrm{~mm} / \mathrm{min}$ & \multirow{3}{*}{$9,6 \mathrm{~L} / \mathrm{min}-16,8 \mathrm{~L} / \mathrm{min}$} \\
\hline & $480 \mathrm{~mm} / \mathrm{hour}-840 \mathrm{~mm} / \mathrm{hour}$ & \\
\hline & 18,9 inchi/hour $-33,1$ inchi/hour & \\
\hline \multirow{3}{*}{ Medium } & $1,7 \mathrm{~mm} / \mathrm{min}-8 \mathrm{~mm} / \mathrm{min}$ & \multirow{3}{*}{$2,04 \mathrm{~L} / \mathrm{min}-9,6 \mathrm{~L} / \mathrm{min}$} \\
\hline & $102 \mathrm{~mm} / \mathrm{hour} \mathrm{-} 480 \mathrm{~mm} / \mathrm{hour}$ & \\
\hline & 4,0 inchi/hour - 18,9 inchi/hour & \\
\hline \multirow{3}{*}{ Low } & $1,07 \mathrm{~mm} / \mathrm{min}-1,7 \mathrm{~mm} / \mathrm{min}$ & \multirow{3}{*}{$1,28 \mathrm{~L} / \mathrm{min}-2,04 \mathrm{~L} / \mathrm{min}$} \\
\hline & $64,2 \mathrm{~mm} /$ hour- $102 \mathrm{~m} /$ hour & \\
\hline & 2,5 inchi/hour- 4,0 inchi/hour & \\
\hline \multirow{3}{*}{ Very Low } & $0 \mathrm{~mm} / \mathrm{min}-1,07 \mathrm{~mm} / \mathrm{min}$ & \multirow{3}{*}{$0 \mathrm{~L} / \mathrm{min}-1,28 \mathrm{~L} / \mathrm{min}$} \\
\hline & $0 \mathrm{~mm} /$ hour - $64,2 \mathrm{~mm} /$ hour & \\
\hline & 0 inchi/hour $-2,5$ inchi/hour & \\
\hline
\end{tabular}

Sumber: Obus (2016)

\section{Formulasi Permeabilitas}

Hukum Darcy menjelaskan tentang ke-mampuan air mengalir pada rongga-rongga (pori) dalam tanah dan sifat-sifat yang mempengaruhi-nya. Ada dua asumsi utama yang digunakan dalam penetapan hukum Darcy ini. Asumsi pertama menyatakan bahwa aliran fluida/cairan dalam tanah bersifat laminar. Sedangkan asumsi kedua menyatakan bahwa tanah berada dalam keadaan jenuh. (Gogot Setyo Budi, 2011)

$$
v=\mathrm{k} . \mathrm{i}
$$


Keterangan :

$\mathrm{v} \quad=$ kecepatan aliran $(\mathrm{m} / \mathrm{s}$ atau $\mathrm{cm} / \mathrm{s}$ )

$\mathrm{k}=$ koefisien permeabilitas

$\mathrm{i} \quad=$ gradien hidrolik

Lalu telah diketahui bahwa:

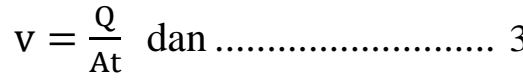

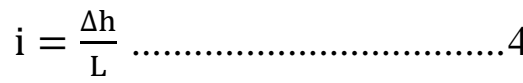

sehingga hukum Darcy bisa dinyatakan dengan persamaan :

$$
\mathrm{Q}=(\text { K. A. t. } \Delta \mathrm{h}) \mathrm{L}
$$

Atau

$$
\mathrm{k}=\frac{\mathrm{QL}}{(\Delta \mathrm{h}) \mathrm{At}}
$$

Keterangan :

$$
\begin{aligned}
\mathrm{A}= & \text { luas penambang melintang } \\
& \operatorname{tanah}(\mathrm{cm} 2) \\
\mathrm{Q}= & \text { Debit aliran (cm3/jam) } \\
\mathrm{t}= & \text { waktu tempuh fluida sepanjang } \\
& \mathrm{L}(\text { detik }) \\
\Delta \mathrm{h}= & \text { ketinggian dari permukaan air } \\
& \text { hingga dasar tabung (cm) } \\
\mathrm{L}= & \text { Ketinggian tabung dalam tanah } \\
& (\mathrm{cm})
\end{aligned}
$$

\section{METODE PENELITIAN}

\section{Lokasi dan Waktu Penelitian}

Penelitian ini dilaksanakan di Laboratorium Hidrologi Teknik Sipil Universitas Muhammadiyah Makassar dan dilakukan pengambilan pada bulan Maret 2017 sampai bulan Oktober 2017.

\section{Sumber Data}

a) Data primer, yakni data yang diperoleh dari hasil simulasi dan pengamatan langsung dari model fisik dan sampel di Laboratorium Hidrologi Teknik Sipil Universitas Muhammadiyah Makassar.

b) Data sekunder, yakni data yang diperoleh dari instansi terkait seperti data curah hujan untuk Wilayah Kota Makassar dari Dinas PU dan BMKG kota Makassar, serta data yang diperoleh dari literatur dan hasil penelitian yang sudah ada, baik penelitian laboratorium maupun penelitian langsung di lapangan yang terkait dengan penelitian ini.

\section{Jenis Penelitian}

Jenis Penelitian ini adalah penelitian eksperimental laboratorium, dengan menggunakan alat rainfall simulator dimana kondisi penelitian ini didesain dan diatur oleh peneliti dengan 
mengacu pada sumber-sumber rujukan/literatur yang berkaitan dengan penelitian tersebut.

\section{Prosedur Penelitian}

Adapun prosedur penelitian yang akan dilakukan adalah sebagai berikut:

1) Tahapan Persiapan

a) Pembersihan,

b) Pengecekan alat dan bahan yang akan diuji,

c) Persiapan perangkat dan instrument yang dibutuhkan, dan

d) Persiapan personil pengamatan serta persatuan persepsi dalam melakukan tindakan pengujian, pengamatan dan pencatatan data.

2) Tahapan penentuan jenis tanah Penentuan jenis tanah dengan melakukan uji karakteristik tanah sesuai dengan tanah yang akan di amati yaitu,tanah umum (common soil).

3) Tahapan Setting media

Sebelum prosedur pengujian model simulasi hujan (rainfall simulator) dilaksanakan perlu dilakukan tahapan setting media pada tangki uji secara lapis perlapis dengan ketebalan perlapis sesuai tinggi sample yang direncanakan, adapun tinggi sampel yang di rencanakan $30 \mathrm{~cm}$ dan setiap $10 \mathrm{~cm}$ di padatka lapis per lapis.

4) Prosedur permeabilitas Prosedur Test ini dimaksudkan untuk menentukan permeabilitas tanah (Common Soil) sebagai berikut :

a) Memeriksa dan menyiapkan tabung test permeabilitas tanah constant head sebelum digunakan.

b) Ambil contoh tanah asli yang tidak terganggu dari bag pengujian Rainfall simulator dengan menggunakan pipa yang sesuai dengan tinggi tabung uji .

c) Memasang batu pori dan kertas filter pada bagian bawah tabung constant head.

d) Memasukkan contoh tanah common soil yang akan ditest

e) Apabila sampel tanah sudah di masukkan, kemudian meletakkan kertas filter dan batu pori diatas sampel tanah tersebut.

f) Setelah selesai memasang 
kertas filter dan batu pori diatas sampel, kemudian tutuplah tabung dengan cara memutar baut yang ada pada penutup tabung uji.

g) Memasukkan air kedalam tabung uji dengan menggunakan corong dan terjadilah aliran air dalam tanah dan memeriksa agar di dalam tabung tidak ada udara sama sekali, untuk mengeluarkan udara yang ada dalam tabung dapat di lakukan dengan membuka dan menutup kran air sampai benar-benar tidak ada udara dalam tabung.

h) Apabila sudah dalam keadaan jenuh, maka mulailah dilakukan pengukuran. Air yang keluar dari dalam tabung uji di tampung dalam gelas ukur, mencatat waktu yang diperlukan untuk mengumpulkan air didalam gelas ukur.

5) Tahapan pengamatan waktu penggenangan.

Running test ke-1. Pengukuran tinggi genangan dan waktu final genangan, frekuensi pertama I5 $_{5}$ Tiap selang waktu 5 menit selama hujan berlangsung waktu penggenangan dan tinggi penggenangan yang tejadi dicatat dalam tabel pengamatan. Sampai tanah dikatakan jenuh, infiltrasi dan run off dinyatakan konstan, lalu hujan buatan dihentikan. Untuk tahapan running test ke-2 sampai dengan running test ke-5 sama dengan tahapan running test ke-1. Kemudian lakukan pembongkaran sampel pada bak percobaaan, untuk dilakukan running test ke-1 untuk intensitas curah hujan I15.

6) Pengolahan Data

Data yang diolah menjadi bahan analisa adalah:

a) Data permeabilitas tanah (K)

b) Waktu durasi penggenagan (ponding time) ( $\mathrm{t}$ ) menit,

c) Tinggi genanagan $(\mathrm{cm})$.

7) Variabel Penelitian

Pada penelitian ini telah ditentukan 2 (dua) variabel, yaitu variabel bebas dan variable. Variabel bebas pada penelitian ini yaitu "Frekuensi Hujan dan Intensitas Curah Hujan”. Variabel terikat pada penelitian ini yaitu "Permeabilitas" dan "waktu penggenangan (Ponding Time)". 


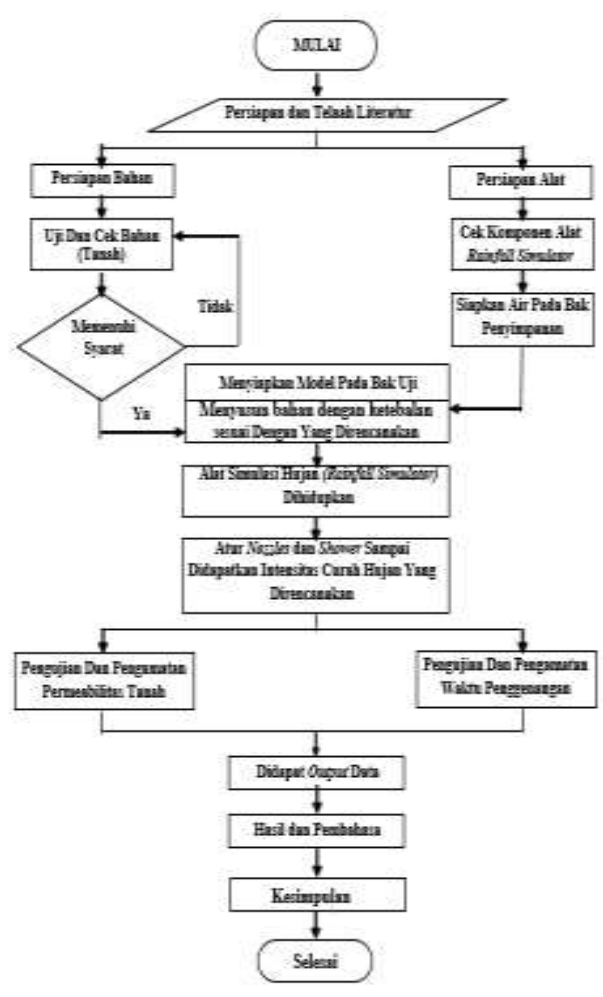

Gambar 2. Bagan Alur Penelitian / Flow Chart

\section{HASIL DAN PEMBAHASAN}

\section{Analisa Intensitas Curah Hujan}

Analisa intensitas hujan menggunakan rumus Mononobe karena data curah hujan yang didapatkan adalah data curah hujan harian.

Rumus Mononobe dengan data curah hujan rencana periode ulang 5 , 15 dan 25 tahun yang didapatkan dari perhitungan berturut-turut : 246,841 $\mathrm{mm}, 307,489 \mathrm{~mm}$ dan $344,900 \mathrm{~mm}$. Contoh perhitungan untuk $\mathrm{t}=5$ menit dapat dilihat pada uraian berikut.

$$
\begin{aligned}
& I_{5}=\frac{135.842}{24}\left(\frac{24}{5 / 60}\right)^{2 / 3}=246.841 \mathrm{~mm} / \mathrm{jam} \\
& I_{15}=\frac{160,339}{24}\left(\frac{24}{5 / 60}\right)^{2 / 3}=307,489 \mathrm{~mm} / \mathrm{jam} \\
& I_{25}=\frac{189.906}{24}\left(\frac{24}{5 / 60}\right)^{2 / 3}=344.900 \mathrm{~mm} / \mathrm{jam}
\end{aligned}
$$

Untuk Perhitungan selanjutnya dijabarkan pada table 2 pada halaman berikutnya.

Tabel 2. Rekapitulasi Hasil Perhitungan Intensitas Curah Hujan Metode Mononobe

\begin{tabular}{ccccc}
\hline No & $\begin{array}{c}\text { Waktu } \\
\text { (menit) }\end{array}$ & $\begin{array}{c}\mathrm{I}_{5} \\
\mathrm{~mm} / \mathrm{jam}\end{array}$ & $\begin{array}{c}\mathrm{I}_{10} \\
\mathrm{~mm} / \mathrm{jam}\end{array}$ & $\begin{array}{c}\mathrm{I}_{25} \\
\mathrm{~mm} / \mathrm{jam}\end{array}$ \\
\hline 1 & 5 & 246,841 & 290,335 & 344,900 \\
\hline 2 & 10 & 155,500 & 182,899 & 217,273 \\
\hline 3 & 15 & 118,669 & 139,578 & 165,811 \\
\hline 4 & 20 & 97,959 & 115,219 & 136,874 \\
\hline 5 & 25 & 84,418 & 99,293 & 117,954 \\
\hline 6 & 30 & 74,757 & 87,929 & 104,454 \\
\hline 7 & 35 & 67,456 & 79,341 & 94,253 \\
\hline 8 & 40 & 61,710 & 72,584 & 86,225 \\
\hline 9 & 45 & 57,050 & 67,102 & 79,713 \\
\hline 10 & 50 & 53,180 & 62,551 & 74,306 \\
\hline 11 & 55 & 49,906 & 58,700 & 69,732 \\
\hline 12 & 60 & 47,094 & 55,392 & 65,802 \\
\hline
\end{tabular}

\section{Hasil Penelitian}

Perbandingan Pengaruh Intensitas Curah Hujan Dan Frekuensi Hujan Terhadap Permeabilitas 
Penyajian data dan analisis permeabilitas dapat dilakukan secara berturut-turut pada tiga variasi intensitas curah hujan rencana kala ulang I5, I15 dan $\mathrm{I}_{25}$, dan variasi frekuensi hujan kala ulangan. Uraian mengenai hasil perbandingan dari proses tersebut disajikan sebagai berikut:

Tabel 3: Perbandingan Pengaruh Intensitas Curah Hujan Terhadap Permeabilitas Tanah :

\begin{tabular}{cccc}
\hline & \multicolumn{3}{c}{$\begin{array}{c}\text { Permeabilitas K (cm/detik), Pada } \\
\text { Intensitas Curah Hujan I }\end{array}$} \\
Frekuensi & \multicolumn{3}{c}{} \\
\cline { 2 - 4 } & $\mathrm{I}_{5}$ & $\mathrm{I}_{15}$ & $\mathrm{I}_{25}$ \\
\cline { 2 - 4 } & $(\mathrm{cm} /$ detik) & $(\mathrm{cm} /$ detik) & $(\mathrm{cm} /$ detik) \\
\hline $\mathrm{F}_{1}$ & 0.0012 & 0.00117 & 0.00114 \\
\hline $\mathrm{F}_{2}$ & 0.00119 & 0.00111 & 0.00107 \\
\hline $\mathrm{F}_{3}$ & 0.00118 & 0.00107 & 0.00101 \\
\hline $\mathrm{F}_{4}$ & 0.00116 & 0.00103 & 0.0010 \\
\hline
\end{tabular}

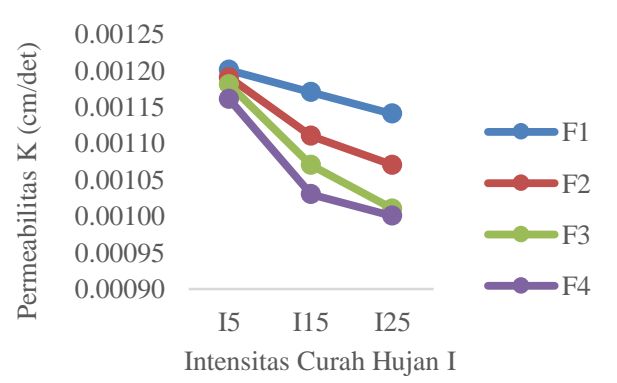

Gambar 3. Perbandingan pengaruh intensitas hujan terhadap permeabilitas.

Tabel 4. Perbandingan Pengaruh Frekuensi Hujan Terhadap Permeabilitas Tanah :

\begin{tabular}{cc}
\hline $\begin{array}{c}\text { Intensit } \\
\text { as I } \\
(\mathbf{m m} / \mathbf{j a} \\
\mathbf{m})\end{array}$ & $\begin{array}{c}\text { Permeabilitas K (cm/detik), Pada } \\
\text { Frekuensi Hujan F }\end{array}$ \\
\hline
\end{tabular}

\begin{tabular}{ccccc}
\hline & $\mathrm{F}_{1}$ & $\mathrm{~F}_{2}$ & $\mathrm{~F}_{3}$ & $\mathrm{~F}_{4}$ \\
\cline { 2 - 5 } & $\begin{array}{c}(\mathrm{cm} / \mathrm{det} \\
\mathrm{ik})\end{array}$ & $\begin{array}{c}(\mathrm{cm} / \mathrm{det} \\
\mathrm{ik})\end{array}$ & $\begin{array}{c}(\mathrm{cm} / \mathrm{det} \\
\mathrm{ik})\end{array}$ & $\begin{array}{c}(\mathrm{cm} / \mathrm{det} \\
\mathrm{ik})\end{array}$ \\
\hline $\mathrm{I}_{5}$ & 0.0012 & $\begin{array}{c}0.0011 \\
9\end{array}$ & $\begin{array}{c}0.0011 \\
8\end{array}$ & $\begin{array}{c}0.0011 \\
6\end{array}$ \\
\hline $\mathrm{I}_{15}$ & $\begin{array}{c}0.0011 \\
7\end{array}$ & $\begin{array}{c}0.0011 \\
1\end{array}$ & $\begin{array}{c}0.0010 \\
7\end{array}$ & $\begin{array}{c}0.0010 \\
3\end{array}$ \\
\hline $\mathrm{I}_{25}$ & $\begin{array}{c}0.0011 \\
4\end{array}$ & $\begin{array}{c}0.0010 \\
7\end{array}$ & $\begin{array}{c}0.0010 \\
1\end{array}$ & 0.0010 \\
\hline
\end{tabular}

Gambar 4. Perbandingan pengaruh

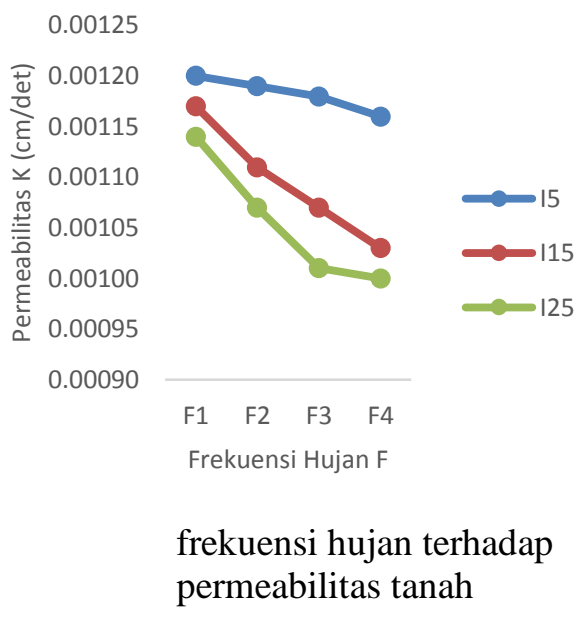

Perbandingan Variasi Frekuensi Hujan Dan Intensitas Curah Hujan Terhadap Waktu Final Genangan.

Penyajian data dan analisis waktu final genangan dapat dilakukan secara berturut-turut pada tiga variasi intensitas curah hujan rencana $\mathrm{I}_{5}, \mathrm{I}_{15}$ dan $I_{25}$ dan lima variasi frekuensi hujan. Uraian mengenai hasil perbandingan dari proses tersebut disajikan sebagai berikut:

Tabel 5. Perbandingan Variasi Frekuensi HujanTerhadap Waktu Final Genangan :

$$
\begin{array}{cc}
\text { Intensit } & \text { Waktu Final Genangan tf (menit), } \\
\text { as I } & \text { Pada Frekuensi Hujan F }
\end{array}
$$




\begin{tabular}{cccccc}
$\begin{array}{c}(\mathbf{m m} / \mathbf{j a} \\
\mathbf{m})\end{array}$ & $\mathrm{F}_{1}$ & $\mathrm{~F}_{2}$ & $\mathrm{~F}_{3}$ & $\mathrm{~F}_{4}$ & $\mathrm{~F}_{5}$ \\
\hline & $\begin{array}{c}(\mathrm{men} \\
\text { it })\end{array}$ & $\begin{array}{c}(\mathrm{men} \\
\text { it })\end{array}$ & $\begin{array}{c}(\mathrm{men} \\
\text { it })\end{array}$ & $\begin{array}{c}(\mathrm{men} \\
\text { it })\end{array}$ & $\begin{array}{c}(\mathrm{men} \\
\text { it })\end{array}$ \\
\hline $\mathrm{I}_{5}$ & 420 & 440 & 460 & 480 & 500 \\
\hline $\mathrm{I}_{15}$ & 440 & 460 & 480 & 500 & 520 \\
\hline $\mathrm{I}_{25}$ & 520 & 630 & 730 & 860 & 1010 \\
\hline
\end{tabular}

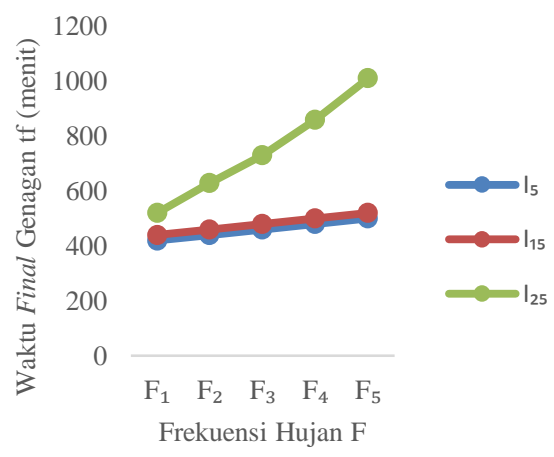

Gambar 5. Perbandingan variasi frekuensi hujan terhadap waktu final genangan.

Tabel 6. Perbandingan Variasi Intensitas Curah Hujan Terhadap Waktu Final Genangan :

\begin{tabular}{|c|c|c|c|}
\hline \multirow{3}{*}{ Frekuensi F } & \multicolumn{3}{|c|}{$\begin{array}{c}\text { Waktu Final Genangan tf } \\
\text { (menit), Pada Intensitas Curah } \\
\text { Hujan I }\end{array}$} \\
\hline & $\mathrm{I}_{5}$ & $\mathrm{I}_{15}$ & $\mathrm{I}_{25}$ \\
\hline & (menit) & (menit) & (menit) \\
\hline $\mathrm{F}_{1}$ & 420 & 440 & 520 \\
\hline $\mathrm{F}_{2}$ & 440 & 460 & 630 \\
\hline $\mathrm{F}_{3}$ & 460 & 480 & 730 \\
\hline $\mathrm{F}_{4}$ & 480 & 500 & 860 \\
\hline $\mathrm{F}_{5}$ & 500 & 520 & 1010 \\
\hline
\end{tabular}

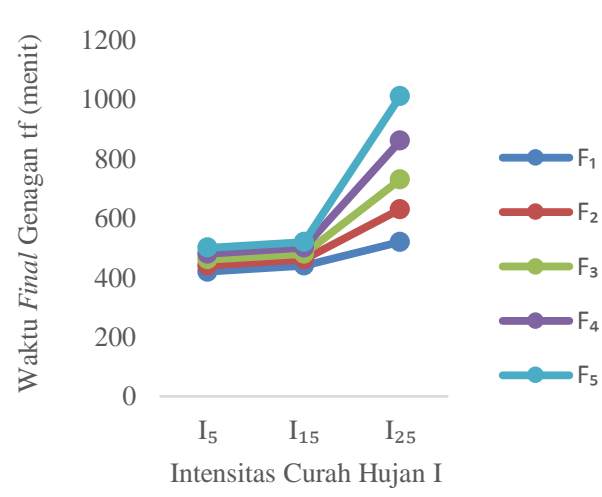

Gambar 6. Perbandingan variasi intensitas curah curah terhadap waktu final genangan

Perbandingan Variasi Intensitas Curah Hujan Dengan Variasi Frekuensi Hujan Terhadap Tinggi Genangan.

Penyajian data dan analisis tinggi genangan dapat dilakukan secara berturut-turut pada tiga variasi intensitas curah hujan rencana I5, I15 dan I25 dan lima variasi frekuensi hujan. Uraian mengenai hasil perbandingan dari proses tersebut disajikan sebagai berikut:

Tabel 7. Perbandingan Variasi Intensitas Curah Hujan Terhadap Tinggi Genangan :

\begin{tabular}{cccc}
\hline & \multicolumn{3}{c}{$\begin{array}{c}\text { Tinggi Genangan hx (cm ), } \\
\text { Pada Intensitas Curah Hujan } \\
\text { I }\end{array}$} \\
\cline { 2 - 4 } & \multicolumn{3}{c}{} \\
\cline { 2 - 4 } & $\mathrm{I}_{5}$ & $\mathrm{I}_{15}$ & $\mathrm{I}_{25}$ \\
\cline { 2 - 4 } & $(\mathrm{cm})$ & $(\mathrm{cm})$ & $(\mathrm{cm})$ \\
\hline $\mathrm{F}_{1}$ & 16.5 & 16.83 & 17.25 \\
\hline $\mathrm{F}_{2}$ & 16.58 & 17 & 17.33 \\
\hline $\mathrm{F}_{3}$ & 16.71 & 17.42 & 17.92 \\
\hline $\mathrm{F}_{4}$ & 16.92 & 17.75 & 18 \\
\hline $\mathrm{F}_{5}$ & 17.08 & 17.92 & 18.54 \\
\hline
\end{tabular}




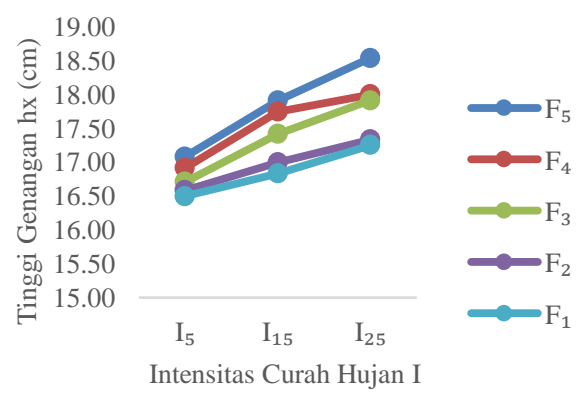

Gambar 7. Perbandingan variasi intensitas hujan dengan tinggi genangan.

Tabel 8. Perbandingan Variasi Frekuensi Hujan Dengan Tinggi Genangan :

\begin{tabular}{cccccc}
\hline \multirow{2}{*}{$\begin{array}{c}\text { Intensit } \\
\text { as I } \\
(\mathbf{m m} / \mathbf{j a} \\
\mathbf{~ m})\end{array}$} & \multicolumn{5}{c}{ Tinggi Genagan hx (cm), Pada } \\
\cline { 2 - 6 } & $\mathrm{F}_{1}$ & $\mathrm{~F}_{2}$ & $\mathrm{~F}_{3}$ & $\mathrm{~F}_{4}$ & $\mathrm{~F}_{5}$ \\
\cline { 2 - 6 } & $(\mathrm{cm})$ & $(\mathrm{cm})$ & $(\mathrm{cm})$ & $(\mathrm{cm})$ & $(\mathrm{cm})$ \\
\hline $\mathrm{I}_{5}$ & 16.5 & 16.58 & $\begin{array}{c}16.7 \\
1\end{array}$ & $\begin{array}{c}16.9 \\
2\end{array}$ & 17.08 \\
\hline $\mathrm{I}_{15}$ & 16.83 & 17 & $\begin{array}{c}17.4 \\
2\end{array}$ & $\begin{array}{c}17.7 \\
5\end{array}$ & 17.92 \\
\hline $\mathrm{I}_{25}$ & 17.25 & 17.33 & $\begin{array}{c}17.9 \\
2\end{array}$ & 18 & 18.54 \\
\hline
\end{tabular}

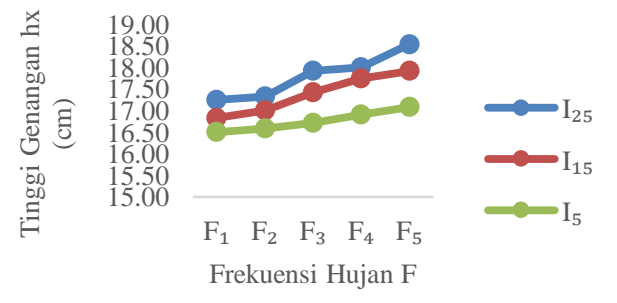

Gambar 8 : Perbandingan variasi frekuensi hujan Dengan tinggi genangan.

\section{PENUTUP}

\section{Kesimpulan}

Nilai koefisien permeabilitas pada tanah common soil berbanding terbalik dengan meningkatnya intensitas curah hujan dan frekuensi hujan, Semakin tinggi variasi intensitas curah hujan dan variasi frekuensi hujan, maka semakin kecil permeabilitas tanah. Tinggi genangan dan Waktu final genangan pada tanah common soil berbanding lurus dengan meningkatnya intensitas curah hujan dan variasi frekuensi hujan.

\section{Saran}

Dalam penelitian ini digunakan intensitas curah hujan wilayah Makassar, dengan periode intensitas curah hujan berulang $\mathrm{I}_{5}, \mathrm{I}_{15}$, dan $\mathrm{I}_{25}$, menggunakan lima kali frekuensi hujan, dan menggunakan jenis tanah common soil, disarankan pada penelitian berikutnya menggunakan intensitas curah hujan wilayah yang berbeda, priode intensitas curah hujan berulang yang berbeda, frekuensi hujan yang berbeda dan jenis tanah yang berbeda

\section{DAFTAR PUSTAKA}

Achmad Sobirin. (2007), Budaya Organisasi (Pengertian, makna dan aplikasinya dalam kehidupan organisasi), Yogyakarta: UPP,STIM YKPN.

AI Wayan Diana, 2004, Studi Rongga Menerus Dan Kinerja Permeabilitas Perkerasan Aspal Porus Lapis Gand, 
Jurnal Transportasi Vol. 4 No. 2 Desember 2004: 85-98.

Andriana Hesti Kusuma, Munifatul Izzati dan Endang Saptiningsih, 2013, Pengaruh Penambahan Arang dan Abu Sekam dengan Proporsi yang Berbeda terhadap Permeabilitas dan Porositas Tanah Liat serta Pertumbuhan Kacang Hijau (Vigna radiata L), Volume XXI, Nomor 1, Maret 2013.

Anugrah Aqsra Bandi, Sumono, Achwil Putra Munir/Program Studi Keteknikan Pertanian, Fakultas Pertanian USU/4 Februari 2014.

A. Rakhim, 2017. The Role Of Tree Root For Increasing Infiltration Capacity. Di Susun Oleh : International Journal Of Civil Engineering And Technology (IJCIET), Volume 8, Issue 8, August 2017

Arifin, Zainal. (2010). Penelitian Pendidikan Metode dan Paradigma Baru. Bandung

Arsyad, S., 1989. Konservasi Tanah dan Air. IPB Press, Bogor.

Ayu Marlina Humairah, 2014,Analisis Hidrolika Bangunan Krib Permeabel Pada Saluran Tanah (Uji Model Laboratorium). Jurnal Teknik Sipil dan Lingkungan Vol. 2. No.3, September 2014
Aziz Alimul, Hidayat. 2007. Metode Penelitian dan Teknik Analisa Data. Jakarta: Salemba Madika.

Bachtiar, E. H., 2011. Ilmu Tanah. USU Press, Medan

Bambang Triadmodjo .1998 Penyusunan Skala Prioritas Pengendalian Banjir Sungai Sungai Dijawa Tengah Selatan. Forum Teknik Jilid 22, No 3. November 1998

Bambang Triatmodjo, 2008. Hidrologi Terapan. Yogyakarta: Beta Offset

Bambang Triadmodjo. (2010), Hidrologi Terapan. Beta Offset. Yogyakarta

Bambang Triatmodjo, 2013,Hidrologi Terapan, Penerbit Beta Offset, Yogyakarta

Burhan Barid, Wahyunika Sari, 2013, Pengaruh Hujan terhadap Perubahan Elevasi Muka Air Tanah pada Model Unit Resapan dengan Media Tanah Pasir. Jurnal Ilmiah Semesta Teknika Vol. 16, No. 1, 57-64, Mei 2013.

Darwis Panguriseng, 2012, Analisis Dan Pemodelan Formasi Pipa Untuk Konservasi Air Tanah Pada Lahan Pertanian Irigasi Air Tanah Di Kabupaten Takalar., Jurnal Teknik Sipil Vol 13 No.3. 